\title{
Evaluation of the use of an "ask-the-expert" e-consultation service for support on health-related requests
}

\author{
N. Nijland ${ }^{\text {ab }}$, J.E.W.C. van Gemert-Pijnen ${ }^{\text {ab }}$, S.M. Kelders ${ }^{\text {ab }}$, B.J. Brandenburg ${ }^{\text {bc }}$, E.R. Seydel ${ }^{\text {ab }}$ \\ ${ }^{a}$ Department of Psychology and Communication of Health and Risk, University of Twente, Enschede, The Netherlands \\ ${ }^{\mathbf{b}}$ Center for eHealth Research (CER), Faculty of Behavioural Sciences, University of Twente, Enschede, The Netherlands \\ ${ }^{\mathbf{c}}$ Medicinfo, Tilburg, The Netherlands
}

\begin{abstract}
E-consultation in health care can be used to respond to an increasing demand for care by offering support on health-related requests. In this study we evaluated the use of an "ask-the-expert" e-consultation service in order to assess whether the service is efficient and useful. A content analysis of e-mail exchange between clients and online health professionals was performed to gain insight in the purposes of use of the service. Our findings show that the e-consultation service was used for health requests on not urgent, minor ailments. Clients asked for health information to increase knowledge on the cause of their injury or disease, its consequences, possible self-care solutions and treatment options. Decision support on assessing the necessity to visit a doctor for a certain health problem was another important reason to use the service. We believe that web-based triage systems could be used to more easily assess whether certain symptoms need to be investigated.
\end{abstract}

\section{Keywords:}

Internet, E-mail, e-consultation, Patient-provider communication, Primary care

\section{Introduction}

Due to demographic and socio-economic trends, a substantial increase in the use of health care facilities is expected in the years to come. This poses a huge burden on human resources. The use of e-consultation in health care -online asynchronous patient-provider communication- may be part of the solution of this future problem because these services have the potential to save unnecessary visits to the general practice by offering self-care solutions [1-4]. These services are particularly useful for certain patient groups such as the elderly and patients with a chronic disease because of their greater need for care and their willingness to use e-consultation [5].

These days, a growing number of websites offer "ask-the-expert" e-consultation services where patients can consult health professionals via secured e-mail. These e-consultation services can be used to direct patients to the most appropriate source of care and away from using unnecessary and ultimately more expensive services. Despite these potentials, the use of e-consultation is not yet widespread in primary care. In order to foster the use of econsultation, we believe that more research is needed on which type of patients actually use e-consultation services, how do they use it and why [5-14].

In this study we evaluated an "ask-the-expert" e-consultation service with so-called type-A interactions; these are encounters in which a pre-existing patient-provider relationship is absent [6,7]. Aim of the study was to assess whether the service is beneficial and efficient for giving support on health-related requests. This paper presents the preliminary results of a content analysis of email exchange between clients and online health professionals. We described the users of the service, the purposes of use, the message content and the efficiency (response time) and usefulness of the service (fulfilment of requests).

\section{Methods}

\section{Description of the e-consultation service}

Since 2001 Medicinfo (http://www.medicinfo.nl) provides an "ask-the-expert" service for medical advice by telephone. The service is offered free of charge to members and clients of homecare organizations and health care insurers. From 2003 the service also provides the possibility to consult nurses and other health professionals online. Depending on fluctuation in workload during the day and week, the service is staffed by a minimum of two and a maximum of five nurses, handling telephone, e-mail and chat-services according to roster. All personnel are registered nurses who have successfully completed a higher vocational training in nursing. All have prior work experience in various health care jobs and most work part time in their present job. They follow an in company communication training and are subject to regular assessments. At all times a physician is on call for consultation.

Before entering their e-mail request via free-text, users have to create a secured personal account for which they have to provide initials, family name, birth date, gender and e-mail address. After 
agreeing with a disclaimer, clients are asked to fill out the purpose of their request on a form:

1. I am looking for: general information about a disease or complaint / a treatment or medical examination / the address of a caregiver or institution;

2. A diagnosis has been established and now I want to know more about the cause / the consequences / the treatment / heredity / possible self care;

3. I want to know if I need to see a doctor for my complaint;

4. My question is about something else.

This classification is based on a content analysis of the "ask-theexpert" service for medical advice by telephone. The incoming email requests are handled by the trained nurses and authorized by a physician. All requests are handled within 2 working days. Some questions are referred to the physician (GP) or to other health professionals. The nurses use standard answer protocols, see Figure 1.

Answer 1 is given for a well-defined health-subject such as "What is a trigger finger". For these "subject" requests general health information is given with links to specific web pages for further information about the subject. If the request is about the specific personal health situation of the client e.g., "I have these symptoms/complaints; what is wrong with me?" no advice can be given because a reliable diagnosis can usually not be established online [6]. For these "personal requests" clients are advised to contact their regular physician, see answer 3 . In some cases the request embraces two aspects: a personal request of a well-defined subject, for example "I have psoriasis, what can I do about it? I heard that psoriasis can be treated with injections, could you tell me more about it?" In these cases answer 2 is given. In case of non-health related requests e.g., questions about the reimbursement of a treatment, answer 4 is given.

Some requests are difficult for nurses to answer, for these requests a GP is consulted. Moreover, specific requests are forward to one out of 25 other health professionals among which are a physiotherapist, psychologist, diabetes nurse, dietician, obstetrician, school doctor, pharmacist, dentist, speech therapist, pedagogue, vaccination expert, and more.

\section{Research instruments}

Log files were used to store nurse-client e-mail exchange during the period of September 2008 until September 2009. A content analysis was performed using the taxonomy of Sittig [15] and Eysenbach and Diepgen [16]. We analyzed 222 e-mail requests handled by nurses in the period of September 2008 and December 2008. To assess the type of health-related requests, Units of analysis were a request and reply exchange which formed a pair of emails.
Answer 1: information or advice

We received your message of (date). In this message you ask information /

advice about ... Please find the information you requested below ...

AND/OR

We have found information about this subject on the following website... If you have remaining questions after reading this information we are pleased to answer them. If this is the case, please contact us again via the website or by telephone.

Answer 2: information or advice AND see regular physician

We received your message of (date). In this message you ask information / advice about ... We can only answer health-related questions if this can be done safely and reliably. After all it concerns your health! To be able to answer your question properly we need extra information that can only be obtained through personal contact with a physician or other caregiver.

Therefore, we recommend contacting your own physician to get an answer for this question. However we did find general information about this subject. Please find it below...

$\mathrm{AND} / \mathrm{OR}$

However we did find general information about this subject on the following website...If you have remaining questions after reading this information we are pleased to answer them. If this is the case you can contact us again via the website or by telephone.

Answer 3: no information or advice, see regular physician

We received your message of (date). In this message you ask information / advice about ...We can only answer health-related questions if this can be done safely and reliably. After all it concerns your health! To be able to answer your question properly we need extra information that can only be obtained through personal contact with a physician or other caregiver. Therefore, we recommend contacting your own physician to get an answer for this question. If you have remaining questions after reading this information we are pleased to answer them. If this is the case you can contact us again via the website or by telephone.

Answer 4: no information or advice, request not health-related

We received your message of (date). Unfortunately we are not able to answer your question. We only answer questions that are related to diseases, health, wellness and lifestyle. For answers on policy and health insurance related questions we advice you to contact the customer service of your health insurance company.

Figure 1 - Standard answers

\section{Results}

\section{Users of the service}

Users of the e-consultation service were predominantly women $(68 \%, 151 / 222)$. Mean age was 44 years $(S D=14.1$, min. age: 14 , max. age: $77, n=166) .8 \%(18 / 222)$ of the e-mail requests were submitted for other persons such as children or the partner.

\section{Reasons to use the service}

Before submitting their request clients had to fill out the reason for their request. The reasons are presented in Table 1. Acquiring more information after a given diagnosis and decision support on whether it is necessary to visit a physician were the main reasons to use the service. Most requests however were categorized by clients as 'something else' $(33.2 \%)$. These requests could nevertheless be classified by the researcher in one of the standard categories, see Table 1. These requests were probably categorized 
by clients as something else because the request was aimed at getting a personal health advice instead of obtaining general health information.

\section{Table 1 - Reasons of clients to use the service (total mentioned reasons $n=247$ )}

\begin{tabular}{lrr}
\hline (1) I am searching for general information about... & $n$ & $\%$ \\
a. a disease or complaint & $\mathbf{3 9}$ & $\mathbf{1 5 . 7}$ \\
b. a treatment or medical examination & 23 & 9.3 \\
c. the address of a caregiver or institution & 9 & 3.6 \\
(2) A diagnosis is given and now I want to know & 7 & 2.8 \\
more about... & $\mathbf{7 3}$ & $\mathbf{2 9 . 6}$ \\
a. the cause of the ailment & 15 & 6.1 \\
b. the consequences of the ailment & 12 & 4.9 \\
c. the treatment of the ailment & 28 & 11.3 \\
d. heredity of the ailment & 3 & 1.2 \\
e. possible self care & 15 & 6.1 \\
(3) I want to know if I need to see a doctor & $\mathbf{5 3}$ & $\mathbf{2 1 . 5}$ \\
(4) My question is about something else & $\mathbf{8 2}$ & $\mathbf{3 3 . 2}$ \\
1a. a disease or complaint & 33 & 13.4 \\
1b. a treatment or medical examination & 7 & 2.8 \\
1c. the address of a caregiver or institution & 2 & 0.8 \\
2b. the consequences of the ailment & 1 & 0.4 \\
2c. the treatment of the ailment & 2 & 0.8 \\
2e. possible self care & 1 & 0.4 \\
4. not health-related (insurance questions) & 36 & 14.6 \\
\hline
\end{tabular}

\section{Type of e-mail requests}

Most e-mail requests submitted to the service $(n=153)$ were about physical complaints, diseases or symptoms (see Table 2). Some examples: "I would like to know how and where I can be treated for definitive depilation of unwanted facial hair", "I'm a woman of X years. My mother has recently been diagnosed with breast cancer for the second time. Her sister has also breast cancer and my grandfather deceased from intestinal cancer. I would like to know whether I should be tested on heredity of (breast) cancer".

A substantial amount of questions were about insurance and reimbursement issues. These questions could not be answered, because the service is only meant for health-related questions.

Table 2 - Categorization of e-mail requests $(n=222)$

\begin{tabular}{lrr}
\hline Type of requests & $n$ & $\%$ \\
Physical complaints, symptoms or diseases & 153 & 68.9 \\
Policy and insurance requests & 27 & 12.2 \\
Medication and treatment & 22 & 9.9 \\
Addresses of physicians or practices & 9 & 4.1 \\
Information on harmfulness of products & 5 & 2.2 \\
Travelers' advice & 2 & 0.9 \\
Lab results & 2 & 0.9 \\
Other & 2 & 0.9 \\
\hline
\end{tabular}

\section{Type of answers and response time}

The response time of the nurses was quick; 94\% (209/222) of the e-mail requests were handled by the nurses within 24 hours. Table 3 presents the type of answers given by nurses. In most cases $(67 \%, 149 / 222)$ general health information or advice was given (Figure 1, answer 1 and 2).

Table 3 - Categorization of answers $(n=222)$

\begin{tabular}{lrr}
\hline Type of answers & $n$ & $\%$ \\
Answer 1: information or advice & 78 & 35.1 \\
Answer 2: information or advice and see physician & 71 & 31.9 \\
Answer 3: no information or advice, see physician & 42 & 18.9 \\
$\begin{array}{l}\text { Answer 4: no information or advice, request not health- } \\
\text { related }\end{array}$ & 31 & 14.1 \\
\hline
\end{tabular}

Health information and advice was provided on

- the ailment itself. For example, Patellofemoral Pain Syndrome, Trigger finger, Tietze Syndrome, "Zurich virus";

- the cause of the ailment. For example, the cause of a toe contusion, the cause of Thrombocytosis;

- the consequences of the ailment e.g., of Paratyphoid fever, Pfeiffer's disease;

- the heredity of the ailment. For example, the heredity of breast cancer;

- self-care options. For example, for fatigue, high cholesterol;

- treatment options. For example, for snoring, excessive smoking, alcohol problems, excessive growth of hair, sleeping problems, weight problems, premature ejaculation, fungal infection of nails, anus pain, scabies, piles, cysts, retractile testis, ADHD, rheumatic disease, Dupuytren's contracture.

In about $20 \%$ of the cases $(42 / 222)$ no information or advice could be given because lack of adequate information to safely do so. In these cases clients were advised to contact their regular physician (answer 3). Most "answer-3" requests were about physical complaints and symptoms without a prior diagnosis given, for example: "Lately, I've got itch during the night over my whole body and I am also thirsty. What could this be? Do I need to see my GP? " In one of these cases the advice to contact the doctor was urgent: "You are advised to see your regular physician today".

Four e-mail requests contained health symptoms that were difficult to evaluate on their seriousness. These requests were judged by a GP on the necessity to see a GP. The results are presented in Figure 2. None of the cases were suitable for e-consultation. These results indicate that clients are really in need for decision support on whether a visit to a regular physician is necessary. 


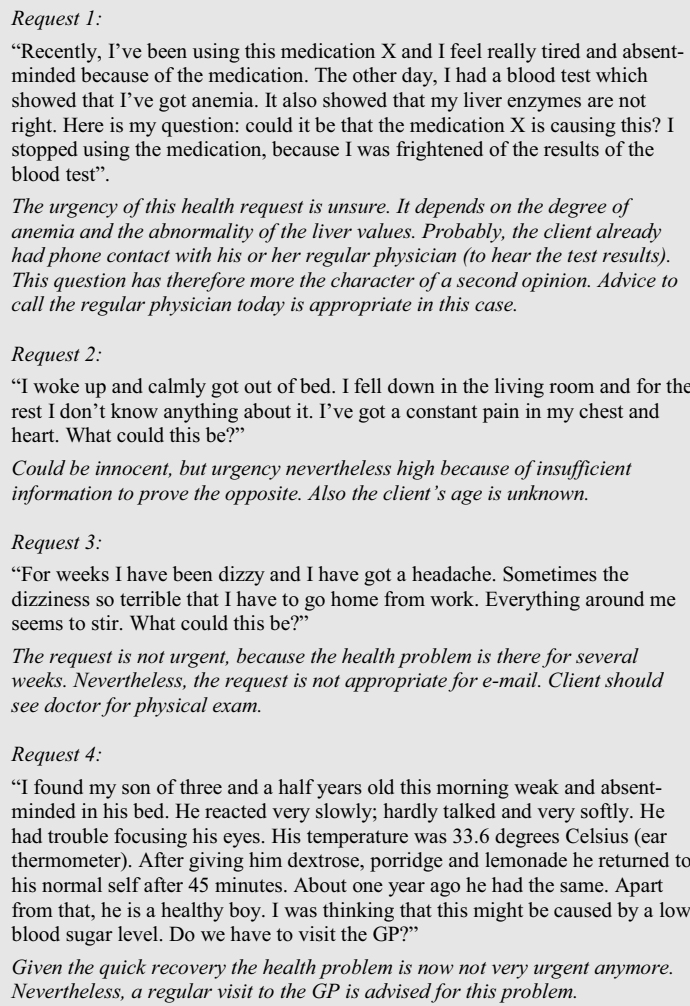

Figure 2 - Assessment of urgency of complaints

\section{Discussion and Conclusion}

In this study we evaluated the use of an "ask-the-expert" econsultation service for advice on health-related requests. We assessed whether the service was efficient and useful for providing health support. This study presented the preliminary results of a content analysis of 222 e-mail messages sent between clients and nurses.

Our results showed that the e-consultation service functioned efficiently; most $(94 \%, 209 / 222)$ requests were handled within 24 hours. The service was also a useful means for providing advice on a broad range of health-related requests. The majority $(69 \%$, 153/247) of the e-mail messages sent by clients concerned requests about physical symptoms, complaints or diseases and could simply be fulfilled by providing general health advice $(68 \%, 149 / 222)$ with the use of standard answer protocols. Another part of the email messages $(19 \%, 42 / 222)$ concerned specific personal health requests e.g., "I have these complaints, what is wrong with me?". However, this kind of personal advice on specific physical symptoms could not be provided adequately because of lack of sufficient or reliable information.

We also found that the service was used for decision support on assessing the necessity to visit a doctor $(21.5 \%, 53 / 247)$. We believe that web-based triage systems can be a useful addition to the service to assess whether certain health complaints need to be investigated by a regular physician. Triage is the process of assessing an individual's health problem and identifying the level of need for clinical care [17]. We think that adding systems for triage of health complaints could increase both the use and usefulness of the service because it facilitates the gatekeepers' function [18].

This paper presented the first results of a broader research on the use of an "ask-the-expert" e-consultation service for support on health-related requests. Notwithstanding the small number of email requests analyzed which limits the external validity of the study, we believe that our study results contributed to the findings of prior studies on the use of e-consultation in primary care $[6,16,13]$. Our findings showed that clients made proper use of the e-consultation service by sending e-mails for non-urgent healthrelated requests on minor ailments. Nurses handled e-mail requests according to the principles for giving Type A (absence of a preexisting patient-provider relationship) advice on the Internet [6]; no specific diagnoses were given, no medicines were prescribed and no general information was given in the guise of individualized information.

Currently, further research is being performed; a content analysis of the e-mail requests handled by other online health professionals such as a GP, dentist, psychologist, etc. A survey is carried out to assess more detailed user characteristics (demographic and healthrelated) to get a more thorough understanding of the reasons for use of the service, to determine the level of client satisfaction with the service and to assess the impact of the service on visits to the general practice.

\section{References}

[1] van Rijen AJG. The Internet user and changes in health care. Statistics Netherlands, 2005 (http://www.rvz.net/data/download/van weten naar doen flycatcher.pdf, last visited 16.4.2009).

[2] Beckjord EB, Finney Rutten LJ, Squiers L, Arora NK, Volckmann L, Moser RP, Hesse BW. Use of the Internet to communicate with health care providers in the United States: estimates from the 2003 and 2005 Health Information National Trends Surveys (HINTS). J Med Internet Res 2007;9(3):e20.

[3] Brooks RG and Menachemi N. Physician use of e-mail with patients: factors influencing electronic communication and adherence to best practices. J Med Internet Res 2006;8(1):e2.

[4] Gaster B, Knight CL, DeWitt DE, Sheffield JV, Assefi NP, Buchwald D. Physicians' use of and attitudes toward electronic mail for patient communication. J Gen Intern Med 2003;18(5):385-389. 
[5] Nijland N, van Gemert-Pijnen JE, Boer H, Steehouder MF, Seydel ER. Increasing the use of e-consultation in primary care: results of an online survey among non-users of econsultation. Int J Med Inform 2009;78(10):688-703.

[6] Eysenbach G. Towards ethical guidelines for dealing with unsolicited patient emails and giving teleadvice in the absence of a pre-existing patient-physician relationship systematic review and expert survey. J Med Internet Res. 2000;2(1):E1.

[7] Umefjord G. Internet consultation in medicine: studies of a text-based Ask the Doctor Service [dissertation]. Umeå University, Umeå, Sweden, 2006.

[8] Nijland N, van Gemert-Pijnen J, Boer H, Steehouder MF, Seydel ER. Evaluation of Internet-based technology for supporting self-care: problems encountered by patients and caregivers when using self-care applications. J Med Internet Res 2008;10(2):e13.

[9] Moore JD, Saywell RM, Thakker N, Jones TA. An analysis of patient compliance with nurse recommendations from an afterhours call center. Am J Manag Care 2002;8(4):343-51.

[10]Flynn D, Gregory P, Makki H, Gabbay M. Expectations and experiences of eHealth in primary care: a qualitative practicebased investigation. Int J Med Inform 2009;78(9):588-604.

[11] Hesse BW, Shneiderman B. eHealth research from the user's perspective. Am J Prev Med 2007 May;32(5 Suppl):S97-103.

[12]Kern J. Evaluation of teleconsultation systems. Intern J Med Inform 2006;75:330-334.

[13]Baker L, Wagner TH, Singer S, Bundorf MK. Use of the Internet and e-mail for health care information: results from a national survey. JAMA 2003;289(18):2400-6.
[14] White CB, Moyer CA, Stern DT, Katz SJ. A content analysis of e-mail communication between patients and their providers: patients get the message. J Am Med Inform Assoc 2004;11(4):260-267.

[15] Sittig DF. Results of a content analysis of electronic messages (email) sent between patients and their physicians. BMC Med Inform Decis Mak 2003;3:11.

[16] Eysenbach G, Diepgen TL. Patients looking for information on the Internet and seeking teleadvice: motivation, expectations, and misconceptions as expressed in e-mails sent to physicians. Arch Dermatol 1999;135(2):151-156.

[17]Derkx HP, Rethans JJ, Muijtjens AM, Maiburg BH, Winkens R, van Rooij HG, Knottnerus JA. Quality of clinical aspects of call handling at Dutch out of hours centres: cross sectional national study. BMJ 2008;337:a1264.

[18] Nijland N, Cranen K, Boer H, van Gemert-Pijnen JE, Seydel ER. Patient use and compliance with medical advice delivered by a web-based triage system in primary care. J Telemed Telecare 2010;16(1):8-11.

\section{Address for correspondence}

Department of Psychology and Communication of Health and Risk, Faculty of Behavioural Sciences,

University of Twente,

P.O. Box 217,

7500 AE Enschede,

The Netherlands.

Tel.: +31 651071559;

fax: +31534894259

E-mail address: n.nijland@utwente.nl (N. Nijland). 